\title{
Cooperation in the Field of Science and Technology Innovation between the CIS Countries
}

\author{
S. M. Gonnova ${ }^{a,}$ * and E. Yu. Razuvaeva ${ }^{a, * *}$ \\ ${ }^{a}$ All-Russian Institute for Scientific and Technical Information (VINITI), Russian Academy of Sciences, Moscow, Russia \\ *e-mail: gonnova@viniti.ru \\ **e-mail: razuvaeva@viniti.ru
}

Received January 26, 2021

\begin{abstract}
Results are presented of research works and implementation activities performed by the All-Russian Institute for Scientific and Technical Information, Russian Academy of Sciences (VINITI RAS), in the status of the CIS Base Organization for Interstate Exchange of Scientific and Technical Information (STI). An overview is given of the institute's international activities to provide information support for the cooperation aimed at creating a common science and technology innovation space and the integration of the information resources available to the national STI Centers of the CIS member states. The role is highlighted of the Interstate Coordination Council for STI in coordinating the CIS member states in the field of STI exchange.
\end{abstract}

Keywords: Commonwealth of Independent States, research, innovation, scientific and technical information, information resources, interstate exchange, CIS Base Organization

DOI: $10.3103 / \mathrm{S} 0147688221030072$

The Commonwealth of Independent States (CIS) has gone through a difficult path of germination and development to become a mechanism for converging positions and developing mutually acceptable solutions on key issues of economics and politics, including in the realm of science and technology innovations.

The All-Russian Institute for Scientific and Technical Information, Russian Academy of Sciences (VINITI RAS; hereinafter referred to as the Institute) in the status of the CIS Base Organization for Interstate Exchange of Scientific and Technical Information carries out research aimed at implementing the fundamental documents of the CIS Economic Council and organizes research works and implementation activities for interstate exchange of scientific and technical information (STI).

Every year, the Institute carries out research and presents progress reports within the government assignments: Development of a system for interstate exchange of STI between the CIS member states (2019-2021, Ministry of Education and Science of Russia), Development of principles of interstate exchange of STI (2016-2018, Ministry of Education and Science of Russia), and The VINITI-facilitated research works and implementation activities for interstate exchange of STI (2010-2015).
One of the important results of the research works carried out within the ongoing interaction of the Institute with the Interstate Coordination Council for Scientific and Technical Information (ICCSTI) and the national Centers for Scientific and Technical Information (STI Centers) of the CIS member states manifests itself as a series of regulatory and methodological documents (drafted and submitted by the Institute) approved by the Council of CIS Heads of Governments. These documents define the priority areas of interstate exchange of STI and formulate coordinated decisions regarding the shared use of information resources:

-Agreement on Cooperation in the Field of Interstate Exchange of Scientific and Technical Information, dated May 30, 2014. Decision of the Council of CIS Heads of Governments. The CIS Internet portal. http://www.cis.minsk.by/reestr/ru/index.html\# reestr/ view/ =4907. Cited January 20, 2020.

-Agreement on the Development of Information Infrastructure for Innovation Activities in the CIS Member States in the Form of a Distributed Information System and the CIS Innovation Information Portal, dated May 19, 2011. Decision of the Council of CIS Heads of Governments. The GARANT.RU Legal Portal. http://www.garant.ru/products/ipo/prime/ doc/71609216. Cited January 20, 2021. 
-On the Interstate Program of Innovative Cooperation between the CIS Member States until 2020, dated December 18, 2011. The Decision of the Council of CIS Heads of Governments and the Decision of the CIS Economic Council as amended on March 18, 2016. The CIS Internet portal. https://ecis.info/cooperation/3119. Cited January 20, 2021.

-The Concept of Research and Information Support for Programs and Projects of the CIS Member States in the Field of Innovations, dated March 13, 2009. Decision of the CIS Economic Council. The CIS Internet portal. https://e-cis.info/cooperation/22467. Cited January 20, 2021.

-The Concept of Formation and Development of an Interstate System for Personnel Training and Retraining and Advanced Professional Development in the Field of Scientific and Technical Information, dated November 20, 2013. Decision of the Council of CIS Heads of Governments. The CIS Internet portal. https://e-cis.info/cooperation/22467. Cited January 20, 2021.

These documents demonstrate the continuity, logical consistency, and the pace of evolution of research topics regarding exchange of information resources on science and technology between the CIS countries.

In addition to the development and promotion of conceptual documents, the Institute, as a CIS Base Organization, implements the approved decisions in accordance with the main documents governing the international cooperation in the exchange of STI.

Since 2007, the Institute has carried out additional research related to the development and improvement of the exchange of STI between the national STI systems of the CIS member states on 11 research topics:

(1) Comparison of the State Subject Heading List of STI (SSSTI) with other classification systems in order to improve the thematic codification system of scientific research and R\&D for civil purposes. Development of a system of links between the various classifiers in the field of STI.

(2) Development and implementation of a comprehensive program of the CIS Base Organization for Interstate Exchange of Primary Sources and Scientific and Technical Information to stimulate the development of international integration processes in the field of science and education in order to facilitate the emergence and growth of stable cooperation links between Russian and foreign research and educational organizations and create of a common shared space for innovative development of Russia and the CIS countries.

(3) Scientific, methodological, organizational, and technical support for the international science and technology conference "Information Society: The State and Trends of Crossborder Exchange of Scien- tific and Technical Information in the CIS," dedicated to the 20th anniversary of the CIS.

(4) Methodological, organizational, and technical support for the 19th meeting of the ICCSTI with the participation of plenipotentiary representatives of the CIS member states.

(5) Scientific, methodological, organizational, and technical support for the 18th meeting of the ICCSTI.

(6) Scientific, methodological, organizational, and technical support for the 17th meeting of the ICCSTI.

(7) Scientific, methodological, organizational, and technical support for the 16th meeting of the ICCSTI.

(8) Providing access for members of the national nanotechnology network to electronic sources of STI required for $R \& D$ in the field of nanotechnology.

(9) Working out a set of measures for the development of an information infrastructure for a national innovation system based on the State System of Scientific and Technical Information.

(10) Improvement of the information structure for the innovation-based integration of the CIS member states within the framework of the international science and technology conference "2007 Scientific and Technical Information.”

(11) Development of an information support system for an innovation-based integration of the CIS member states.

The studies to identify new organizational forms of cooperation created the foundations for the conceptual documents and agreements aimed at increasing the technological level and competitiveness of science-based production, facilitating the entry of innovative products to the domestic and foreign markets of the CIS countries, supporting research ties, and maintaining the common principles in the development of science.

The creators of these documents made use of the best practices of the USSR State System of Scientific and Technical Information, as well as the republican, sectoral, and intersectoral STI systems of that time. After adapting to modern conditions, these systems have continued to interact in the field of information support for research and innovation in the CIS member states.

The Institute received the status of a CIS Base Organization largely because of the results of its extensive research on CIS-related topics within government assignments, government contracts, and agreements signed with the Presidium of the Russian Academy of Sciences and the Ministry of Education and Science of Russia. The main credit for creating the CIS Base Organization goes to Lyudmila Borisova (Dr. Sci. (Biol.)), the VINITI Deputy Director for Science, the plenipotentiary of the Russian Federation at the 15th, 16th, 17th, and 18th ICCSTI meetings, and the head of the Working Group under the ICCSTI Chairman, 
as well as the staff of the VINITI Department of Innovations and Targeted Scientific Information Research.

As of today, within the government assignment entitled Development of a system for the interstate exchange of STI between the CIS member states (2019-2021, Ministry of Education and Science of Russia), the Institute has carried out the following research works:

-development of the State System of Scientific and Technical Information of the Russian Federation and of the Republic of Belarus;

- condition assessment of the STI sector in individual CIS countries: the Republic of Kazakhstan, the Kyrgyz Republic, and the Russian Federation;

- analysis of the national STI systems of the CIS member states;

- review of the main documents and participants of international cooperation in the field of science and technology innovation within the CIS.

Analytical materials and documents were prepared for meetings of the CIS Executive Committee and research papers were published on the results of these works. Their scientific novelty lies in the fact that this research was the first assessment of the current condition of the national STI systems in the CIS in the following categories: regulatory and legal framework, public administration model, infrastructure, and core resources and participants in the international cooperation of the CIS member states.

The scientific novelty of the research topic Development of a system for the interstate exchange of STI between the CIS member states resides in the creation and implementation of a methodology for a state-centered approach to the development of science and technology cooperation between the CIS countries; in the search for ways of effective implementation of the international agreements within the CIS decisions aimed at creating a common science and technology innovation space and integrating the information resources of the national STI Centers; and in the refinement of the principles, methods, and tools of interstate exchange of STI. Research works on this topic lie within the priority areas of the Strategy for Scientific and Technological Development of the Russian Federation and aim at creating an efficient interstate STI system, integrating the latter into the global information space and promoting the creation of a market for information products and services.

Marking the 30th anniversary of the establishment of the CIS, the Institute, as the CIS Base Organization for Interstate Exchange of STI, has reviewed the outcomes of its works by presenting the following documents:

-fourteen annual reports on research work, containing the main theoretical and experimental results obtained within government assignments on CIS- related issues from the Ministry of Education and Science, the Federal Agency for Scientific Organizations, and the Presidium of the Russian Academy of Sciences (2007-2021);

-twenty-eight reports on CIS-related R\&D projects within 11 additional government contracts and agreements with the Ministry of Education and Science and the Presidium of the Russian Academy of Sciences;

-materials of 21 applications for CIS-related studies, prepared and submitted to the Ministry of Education and Science for participation in the competitions of the federal target programs Research and Development in the Priority Areas of the Science and Technology Complex of Russia for 2007-2013 and Research and Development in the Priority Areas of the Science and Technology Complex of Russia for 2014-2020;

- the Comprehensive Program of the CIS Base Organization for Interstate Exchange of STI;

- participation and preparation of materials for 13 meetings of the ICCSTI and the CIS Economic Council, including research, methodological, organizational, and technical support for six meetings of the ICCSTI.

- ongoing interaction with the national STI Centers: review and analysis of proposals from the CIS member states on further development of the national information systems;

- participation in the development of a series of fundamental documents adopted by the Council of CIS Heads of Government;

- preparation of ten analytical reviews for the volumes of the CIS Executive Committee;

- organization of seven international STI conferences, including 12 seminars on professional development in the field of STI for representatives of the CIS member states;

- participation in more than 30 international STI conferences;

-development and updating of the CIS Internet portal for the international exchange of STI Information for innovative activities of the CIS member states (CIS Internet portal) [1];

-development and maintenance of the ICCSTI website [2].

In the capacity of the CIS Base Organization for Interstate Exchange of STI, the Institute continues to prepare, disseminate, and apply information resources across the CIS space; subscribes organizations of the CIS member states to the VINITI abstract journal and databases; facilitates the exchange of primary sources, i.e., periodical publications of the CIS member states; and provides access to traditional sources in print and in electronic format (including electronic publications (EPs) and databases (DBs) provided locally). 
Having access to the state information resources, the Institute compiles them in an electronic catalog containing full information on the results of recording the inflow of scientific and technical literature: articles, books, deposited manuscripts, abstracts of dissertations, full texts of dissertations, regulatory and patent documents; organizations and personalities; SSSTI rubrics; descriptions of publication series. The Institute's archives contain scientific publications of all types (periodical and continuing, collections of papers, materials of scientific events, monographs, textbooks for universities, deposited works, abstracts of dissertations, etc.), periodicals from other libraries (Library for Natural Sciences, Russian Academy of Sciences; Russian National Public Library for Science and Technology, etc.), and foreign and Russian electronic periodicals available to the Institute on the platforms of publishing houses and owners of electronic resources, etc. The Institute's electronic catalog contains more than 1.5 million documents accessible using a DOI.

On an ongoing basis, the CIS Base Organization prepares materials on problems of interstate exchange of STI for publication in scientific journals that are released either by the Institute itself or with its participation. For example, the Institute publishes review volumes, newsletters, and journals, such as Scientific and Technical Information Processing; Automatic Documentation and Mathematical Linguistics; Mezhdunarodnyi Forum po Informatsii; Ekonomicheskaya Nauka v Sovremennoi Rossii; Integrirovannaya Logistika; Problemy Bezopasnosti i Chrezvychainykh Situatsii; Problemy Bezopasnosti Poletov; Transport: Nauka, Tekhnika, Upravlenie; Ekonomika Prirodopol'zovaniya; an abstract journal Ekonomiya Energii; etc. Six of these publications are included in the list of leading peerreviewed journals, in which authors who are applying for science degrees (Doctor of Sciences and Candidate of Sciences) are required to publish their results.

In the capacity of the CIS Base Organization for Interstate Exchange of STI, the Institute facilitates the exchange of scientific and technical literature in print and electronic format within the Agreement on Cooperation in the Field of Interstate Exchange of STI.

The Institute carries out the search, selection, and processing of materials for publication in the scientific journal Mezhdunarodnyi Forum po Informatsii with the aim of their subsequent posting on the CIS Internet portal [1]. This journal (four issues per year) is intended to discuss topical problems of information theory and practice, which are of interest to a wide range of specialists from different countries. It covers the following topics: information policy; science communication; development trends in forms of presentation and dissemination of information (multimedia and hypermedia); forecasting of the development and use of information systems, services, and networks (international, regional, and national); development and operation of databases; theoretical foundations of computer science; classifications and information languages; information needs; training of information workers; information consumer awareness; bibliometrics; and information value and quality. The journal publishes original and translated articles; congress and conference proceedings; reviews of books and personalities; brief communications; letters; and advertisements. The Institute is interested in cooperating with scientists and specialists from the CIS member states and invites them to submit their manuscripts on the problems of interstate exchange of STI for publication in its journal.

One important result of the research work of the Institute as the CIS Base Organization for Interstate Exchange of STI is 76 research papers on CIS-related topics; a half of these papers were published in journals indexed in the Scopus and Web of Science databases. The scientific novelty of these papers reflects the research results and the proposals for increasing the efficiency of interstate exchange of STI between the CIS member states.

During the pandemic, while providing information support in the field of fundamental and applied science and technology, the Institute promptly analyzed a large number of relevant science documents including biological, chemical, and medical aspects as well as social and economic impacts of coronavirus infection COVID-19. In 2020, the Institute published two special issues of an interdisciplinary volume of information and analytical papers COVID-19 Pandemic: Biology and Economics [3] and COVID-19 Pandemic: Chemistry and Economics [4].

At present, the Institute pays special attention to the support of the Internet portal for the international exchange of STI Information for innovative activities of the CIS member states [1] using the system of national resource portals in compliance with the laws of the corresponding countries. The portal was designed by the Institute jointly with the STI Centers of Armenia, Belarus, Kazakhstan, Kyrgyzstan, Moldova, and Tajikistan on the basis of international cooperation documents in the field of interstate exchange of STI. The CIS Internet portal provides access to various types of information resources. The CIS Base Organization facilitates the operation and upgrade of the CIS Internet portal.

The main goal of the CIS Internet portal is to provide the necessary information and analytical data to the participants of innovation processes in the CIS member states at all stages of the development and promotion of innovative products and technologies.

The objectives of the CIS Internet portal:

-creation of a common shared electronic platform of the CIS member states, which integrates the infor- 
mation on resources and services in the field of science, technology, innovation, and education;

-information interaction of the scientific community with government bodies, businesses, and educational institutions;

-information support for interstate exchange in the field of STI.

Maintaining the CIS Internet portal, the Institute collects, processes, stores, and provides scientific and technical innovation-related resources and contributes to the development of research works, refinement of terminology, determination of innovation progress indicators in science and technology, and formation of target user groups.

The Internet portal is unique in terms of its content and scope of the national information resources, which cover such countries as Belarus, Moldova, Kazakhstan, Tajikistan, Russia, Armenia, Uzbekistan, and Kyrgyzstan.

The implementation of the main international documents on cooperation in the field of interstate exchange of STI is aimed at solving the problem of integrating the national STI systems of the CIS countries into the international information space.

The field of application of the research results obtained by the Institute is the international relations of Russia on the development of science and technology cooperation with the CIS countries, including the search for methods of efficient implementation of CIS agreements and decisions of the Council of CIS Heads of State and the Council of CIS Heads of Governments, which are aimed at forming a common science and technology innovation space and integrating information resources of national STI Centers, make a substantial contribution to the development of international cooperation of the CIS, and are of international importance.

The Institute actively participated in the implementation of the Action Plan for the third stage (2016-2020) of the CIS Economic Development Strategy for the Period until 2020.

Based on the results of the annual ICCSTI meetings, where the Institute regularly presents its reports On the activities of the CIS Base Organization for Interstate Exchange of STI and On the condition of the CIS information portal for innovative activities of the CIS member states, the Institute has always received approval and positive appraisal by ICCSTI members. Within the research works on the government assignment, the CIS Base Organization takes an active part in the preparation of analytical documents and official resolutions and maintains the ICCSTI website [2]. The recent meetings of the ICCSTI were able to draw the attention of government bodies to the issue of improving national STI systems and contributed to the development of innovative activities and the use of international experience of the CIS member states. Members of the ICCSTI regularly inform one another about the main national events in the field of STI, which provide scientists and specialists with a venue to present their reports and information materials.

Thus, in accordance with its tasks, the Institute actively participates in Russia's international projects on the development of scientific and technical cooperation with the CIS member states to strengthen integration processes within the CIS. Together with the ICCSTI and national STI Centers, the Institute participates in the improvement of STI exchange and development of a common science and technology innovation space for the CIS.

An analysis of the Institute's work outcomes since the time it received the status of a CIS Base Organization shows that it has generally fulfilled the tasks assigned to it at certain periods of time. However, the current international situation and the transformation of the CIS national economies require the development of sectoral and intersectoral cooperation and a substantial increase in the efficiency of information support for science and technology innovation and for the exchange of resources between the CIS member states.

The attention of the Institute's researchers is focused on the study of the various factors that influence the system of interstate exchange of STI between the CIS member states and the development of integration interactions in the post-Soviet space.

While focusing on the development of fundamental research in the field of informatics and information technology within the government assignments, the Institute also carries out extensive practical activities, working in close contact with the ICCSTI and the national SCI Centers of the CIS member states within the framework of the new conceptual documents, i.e., the CIS Economic Development Strategy for the Period until 2030, ${ }^{1}$ the Interstate Program of Innovative Cooperation of the CIS Member States until $2030,{ }^{2}$ and the Concept of International Scientific and Technical Cooperation of the Russian Federation. ${ }^{3}$ This approach will allow the Institute to achieve meaningful theoretical and practical results aimed at the creation of a common science and technology

\footnotetext{
${ }^{1}$ The CIS Economic Development Strategy for the Period until 2030. Decision of the Council of CIS Heads of Government of May 29, 2020. https://e-cis.info/page/3762/. Cited January 24, 2021.

2 The Interstate Program of Innovation Cooperation between the CIS Member States until 2030. Decision of the Council of CIS Heads of Government of November 6, 2020. https://ecis.info/page/3372/90802/. Cited January 24, 2021.

${ }^{3}$ The Concept of International Cooperation in Science and Technology of the Russian federation. February 8, 2019, no. TG-P8952. https://minobrnauki.gov.ru/about/deps/dms/mntsii/. Cited January 22, 2021.
} 
innovation space and the integration of information resources of the CIS national STI Centers.

\section{FUNDING}

This work was performed within the government assignment of the All-Russian Institute for Scientific and Technical Information (VINITI), Russian Academy of Sciences, no. 0003-2019-0004.

\section{REFERENCES}

1. Internet-portal of CIS on international exchange of scientific and technical information "Information for in- novative activity of states-participants of CIS". www.sng.viniti.ru/. Cited January 16, 2021.

2. Executive Committee of CIS International Coordinative Council on Scientific and Technical Information. https://www.mksnti.ru. Cited January 16, 2021.

3. "Pandemic COVID-19. Biology and Economics". Interdisciplinary special issue of the information-analytic collection. http://www.viniti.ru/. Cited January 16, 2021.

4. "Pandemic COVID-19. Chemistry and Economics". Interdisciplinary special issue of the information-analytic collection. http://www.viniti.ru/. Cited January 16, 2021.

Translated by A. Kobkova 